\title{
Concomitant Increases of the Developing Seed Phosphoenolpyruvate Carboxylase Activity and the Seed Protein Content of Field-Grown Wheat with Nitrogen Supply
}

\author{
Naoki Yamamoto ${ }^{12^{*} \#}$, Toshio Sugimoto ${ }^{1^{*}}$, Takehiro Masumura ${ }^{2,3^{\dagger}}$ \\ ${ }^{1}$ Plant Nutrition Laboratory, Department of Biological and Environmental Science, Faculty of Agriculture, \\ Graduate School of Agricultural Science, Kobe University, Kobe, Japan \\ ${ }^{2}$ Laboratory of Genetic Engineering, Graduate School of Life and Environmental Sciences, Kyoto Prefectural \\ University, Kyoto, Japan \\ ${ }^{3}$ Kyoto Prefectural Institute of Agricultural Biotechnology, Kyoto, Japan \\ Email: ${ }^{\dagger}$ masumura@kpu.ac.jp
}

Received 20 October 2014; revised 27 November 2014; accepted 9 December 2014

Copyright (C) 2014 by authors and Scientific Research Publishing Inc.

This work is licensed under the Creative Commons Attribution International License (CC BY).

http://creativecommons.org/licenses/by/4.0/

(c) () Open Access

\begin{abstract}
Wheat seed storage protein is of great importance for human food. To increase the contents of storage proteins effectively, nitrogen fertilizer at flowering stages is commonly applied. In our previous study, rice phosphoenolpyruvate carboxylase (PEPCase) activity in developing seeds was observed in response to nitrogen application at a flowering stage and was positively correlated to the response of the protein content in seeds of six cultivars. This observation might indicate that the seeds have a biological system for accepting nitrogen in seeds by using PEPCase. To test whether this physiological event occurs in wheat, we examined the PEPCase activity and protein content in field-grown wheat seeds under different nitrogen supply conditions. With only basal dressing, seeds showed lower PEPCase activity and protein content (both 0.90 -fold) compared to seeds without basal fertilizer. With ammonium sulfate application at 8.3 and $25 \mathrm{~g} / \mathrm{m}^{2}$ at a flowering stage, seeds showed higher PEPCase activity (1.08- and 1.17-fold, respectively) and protein content (1.15- and 1.42-fold, respectively), depending on the nitrogen level. We investigated the relationship between PEPCase activity and protein content in the seeds among four conditions. The effect of the nitrogen supply on PEPCase activity during grain-filling stages was validated by the results of a hydroponic culture experiment. Together the results demonstrate that our hypothesis seems to apply to field-grown wheat.
\end{abstract}

\footnotetext{
*These authors contributed equally to this work.

"Present address: Bioinformatics Laboratory, School of Agriculture, Meiji University, Kanagawa, Japan.

${ }^{\dagger}$ Corresponding author.
}

How to cite this paper: Yamamoto, N., Sugimoto, T. and Masumura, T. (2014) Concomitant Increases of the Developing Seed Phosphoenolpyruvate Carboxylase Activity and the Seed Protein Content of Field-Grown Wheat with Nitrogen Supply. Agricultural Sciences, 5, 1558-1565. http://dx.doi.org/10.4236/as.2014.514167 


\section{Keywords}

\section{Nitrogen Application, Phosphoenolpyruvate Carboxylase, Seed Storage Protein, Wheat}

\section{Introduction}

Wheat seeds are an excellent food source. The seeds contain storage proteins, gliadins and glutenins, which have the unique properties and play important roles during the food processing of wheat flour [1]. Because of its proteins, wheat flour can be used in a wide range of foods such as bread and noodles. The proteins are the most critical component in the determination of flour quality [2]. The composition and content of the storage proteins have been targeted in wheat cultivation and breeding [3]. Genetic breeding research regarding protein composition and the environmental modulation of the protein content has led to the efficient production of agronomically valuable wheat seeds [1] [4] [5].

The application of nitrogenous fertilizer is a well-validated technique for achieving a high seed yield and the enhancement of the seed protein content in wheat [6]-[8]. Nitrogen, one of the primary nutrients, affects plant growth positively in general. An adequate nitrogen supply leads to higher photosynthetic activity in source organs. In addition, assimilated nitrogen is transported into seeds during the grain-filling stages, and consequently, the content of the seed storage proteins is increased.

High activity of phosphoenolpyruvate carboxylase (PEPCase, EC4.1.1.31) has been observed in the seeds of many crops, indicating that this enzyme plays some crucial roles in seeds. The enzyme catalyzes the $\beta$-carboxylation of phosphoenolpyruvate to produce oxaloacetate, which is involved in amino acid synthesis, fatty acid synthesis, and respiration [9]. In C3 plants, several studies emphasized the potential contribution of PEPCase to nitrogen metabolism in developing seeds. For example, we observed a positive correlation between PEPCase activity and the storage protein content in the seeds of several cultivars of soybean [10]. PEPCase activity in developing rice seeds was observed in response to nitrogen fertilization, and it was correlated with the response of nitrogen content in mature seeds among six rice cultivars [11]. A candidate causal isogene involved in nitrogen accumulation in rice seeds was identified by a molecular analysis [12]. A transgenic study of a bacterial PEPCase gene in narbon beans revealed that an increase of the amino acid content in developing seeds, resulting in higher protein content in the seeds [13].

To date, PEPCase in developing wheat seeds has been characterized by immunological strategies. Araus et al. [14] described the localization of the enzyme in the aleurone layer cells of a durum wheat cultivar. The expression and localization of PEPCase protein in common wheat seeds were investigated [15]. However, the biological function of PEPCase in developing wheat seeds is still unclear.

The goal of the present study was to examine the effect of different levels of nitrogen supply on both the PEPCase activity in maturing seeds and the protein content in mature seeds in wheat. We cultivated wheat plants under four different nitrogen supply conditions, and we analyzed the PEPCase activity in the harvested developing seeds and the protein content in the mature seeds. This paper is the first report on the results of an investigation into the relationship between PEPCase activity and protein content in seeds in multiple field growth conditions. We also tested the effects of nitrogen and light supply on the PEPCase activity in developing seeds from hydroponically grown wheat plants. Our results provide insights into the mechanisms underlying the response of seeds' protein content to the nitrogen supply.

\section{Materials and Methods}

\subsection{Plant Materials}

A common wheat (Triticum aestivum L.) variety, Norin 61, which is one of the main modern cultivars in Japan, was grown in an experimental field at Kobe University in 1997. To monitor the effect of the nitrogen supply, we set four experimental plots. In the first plot, named "No-basal", a chemical fertilizer (N:P:K = 8:8:8) was not dressed before cultivation. In the second plot, named "Low-N", the same chemical fertilizer was dressed at the density of $8 \mathrm{~g} / \mathrm{m}^{2}$ for each nutrient before cultivation, but no nitrogen fertilizer was applied at the heading date. The third and fourth plots were named "Middle-N" and "High-N", respectively. In both plots, the same chemical fertilizer was dressed before cultivation, and nitrogen fertilizer was applied on the soil surface at the heading 
date. In the Middle-N plot, ammonium sulfate at $8.3 \mathrm{~g} / \mathrm{m}^{2}\left(0.88 \mathrm{~g} / \mathrm{m}^{2}\right.$ of nitrogen) was applied. In the High-N plot, ammonium sulfate at $25 \mathrm{~g} / \mathrm{m}^{2}\left(2.65 \mathrm{~g} / \mathrm{m}^{2}\right.$ of nitrogen) was applied.

Seeds were soaked on water on May 17, 1997 and incubated at $4^{\circ} \mathrm{C}$ for 1 week to induce germination. The seeds were sowed onto the field. The heading date was May 19th. Seeds that were developing on June 11th were harvested and frozen immediately in liquid nitrogen for storage at $-20^{\circ} \mathrm{C}$ until use. On June 16th, we collected panicles and flag leaves and froze them in liquid nitrogen after measuring their fresh weights. Mature seeds were sampled at the beginning of July and weighed.

Hydroponically grown wheat was also prepared at a normal greenhouse at Kobe University in 1998 spring. On February 1st, wheat seeds were sterilized by $1 \%$ sodium hypochlorite and then sandwiched between two pieces of moist filter papers. After incubation at room temperature for 10 days, germinated seeds were planted in one-half-strength Hoagland solution [16]. After 2 weeks of cultivation, the wheat plants were transferred into Hoagland solution. The hydroponic solution was freshened once a week. On the flowering date (April 18th), on which $50 \%$ of flowers were in bloom, the plant growth environment was changed by modifying the final concentration of ammonium nitrate and using cheesecloth with the following four experimental plots: 1) low nitrogen under normal sunlight (Low-N-L); 2) low nitrogen under shade (Low-N-S); 3) high nitrogen under normal sunlight (High-N-L); and (4) high nitrogen under shade (High-N-S). In the Low-N-L and Low-N-S plots, the final concentration of ammonium nitrate was decreased from 80 to $12 \mathrm{mg} / \mathrm{L}$, resulting in the total nitrogen concentration $214 \mathrm{mg} / \mathrm{L}$. In the High-N-L and High-N-S plots, the final concentration of ammonium nitrate was increased to $240 \mathrm{mg} / \mathrm{L}$, resulting in $294 \mathrm{mg} / \mathrm{L}$ as the total nitrogen concentration. In the Low-N-S and High-N-S plots, the plants were covered by cheesecloth to cut $50 \%$ of the sunlight. Developing seeds at 26 days after flowering were collected for the PEPCase assay.

\subsection{Protein Determination}

The protein content in the mature seeds was determined by the Kjeldahl method [17]. The protein amount was calculated from the total nitrogen by using the general factor of 6.25 .

\subsection{PEPCase Assay}

Developing seeds of 10 gains were homogenized in an extraction buffer [100 mM Tris-HCl, pH 7.8, $1 \mathrm{mM}$ EDTA, 1 mM, 2-mercaptoethanol, 10\% (w/v) glycerol] with Complete Protease Inhibitor Cocktail (Roche, Basel, Switzerland) at $4^{\circ} \mathrm{C}$. The homogenate was centrifuged at $13,000 \mathrm{~g}$ for $15 \mathrm{~min}$, and the supernatant was collected for the PEPCase assay.

PEPCase activity was assayed by coupling with a malate dehydrogenase reaction according to Echevarria's method with modifications [18]. This assay was performed in $1 \mathrm{~mL}$ of a medium containing $50 \mathrm{mM}$ Tricine$\mathrm{KOH}, 5 \mathrm{mM} \mathrm{MgSO}_{4}, 0.15 \mathrm{mM}$ NADH, $5 \mathrm{mM} \mathrm{KHCO}_{3}, 5 \mathrm{mM}$ PEP (cyclohexylammonium salt), $4 \mathrm{mM}$ DTT and $1.5 \mathrm{U}$ pig heart malate dehydrogenase at $25^{\circ} \mathrm{C}$ at $\mathrm{pH} 8.3$. The decreasing rate of the absorbance at $340 \mathrm{~nm}$ was measured. One unit of enzyme activity is defined as the amount of PEPCase catalyzing the production of $1 \mu \mathrm{mol}$ of oxaloacetate/min at $25^{\circ} \mathrm{C}$. The assay was carried out twice for each sample, and the average of measured values was adopted.

\section{Results}

\subsection{Plant Growth}

We set four growth conditions with different nitrogen supplies as described in the Plant Materials section: Nobasal (without no basal fertilizer), Low-N (with the basal fertilizer), Middle-N (with the basal fertilizer and 0.88 $\mathrm{g} / \mathrm{m}^{2}$ nitrogen) and High-N (with the basal fertilizer and $2.65 \mathrm{~g} / \mathrm{m}^{2}$ nitrogen). To monitor the plant growth in the experimental plots, we weighed the panicles, flag leaves and mature seeds in each plot (Table 1). The fresh weights of the panicles and flag leaves per plant were greatly increased in the order No-basal $<$ Low- $<<$ Middle$\mathrm{N}<$ High-N. The increases of these two parameters were in parallel. This result indicates the nitrogen use status. The weight in mature seeds per 100 grains also showed increases, in the same order of plots.

\subsection{Variation of PEPCase Activity}

We determined the PEPCase activity in the developing seeds per fresh weight and per grain. The activities per 
Table 1. Effect of nitrogen on the growth of the panicles, flag leaves and mature seeds per plant.

\begin{tabular}{ccccc}
\hline Sample & No-basal & Low-N & Middle-N & High-N \\
\hline Panicle $^{*}$ & 0.476 & 1.177 & 1.427 & 1.930 \\
Flag leaf & 0.051 & 0.133 & 0.151 & 0.191 \\
Mature seed & 3.376 & 3.504 & 3.660 & 3.705 \\
\hline
\end{tabular}

*The panicle and flag leaf data are weight (g) per plant, and those in the mature seed are weight per 100 grains.

fresh weight (FW) in all of the plots were distributed around 1.0 U/g FW (Figure 1(a)). Among the three plots with the basal fertilizer, the activity was increased according to the nitrogen supply at the flowering stage. However, in the No-basal plot, activity was observed that was clearly higher than that of the Low-N plot and similar to that of the Middle-N plot. The activities per grain showed a different trend (Figure 1(b)), namely, the activities in the No-basal and Low-N plots were quite similar, although increased activity according to the nitrogen supply at the flowering stage was seen. These results showed that the application of nitrogen fertilization at the flowering stage was an effective strategy to induce an increase in PEPCase activity. The different patterns of PEPCase activity in the No-basal plot might indicate that basal fertilization caused a different carbon/nitrogen balance in the grain-filling stages.

\subsection{Variation of Seed Storage Protein Content}

The protein content in the mature seeds was predicted from the nitrogen content determined by the Kjeldahl method. The lowest protein content was observed in the Low-N plot, and the highest protein content was observed in the High-N plot (Figure 2). The No-basal and Middle-N plots showed similar protein content values. The ammonium nitrogen applications of 8.3 and $25 \mathrm{~g} / \mathrm{m}^{2}$ at the flowering stage resulted in 1.15- and 1.42-fold increases in the seed protein content, respectively, compared to the Low-N plot.

\subsection{Relationship between PEPCase Activity and Protein Content}

We observed a rough relationship between the PEPCase activity and protein content in the four experimental plots (Figure 3). When we compared the activity per fresh weight, a linear correlation was apparent among the three plots with the basal fertilizer. This result was consistent with the concept that basal fertilization causes different carbon/nitrogen balances in grain-filling stages. In contrast, when we compared the activity per grain, the data of all four plots showed a linear correlation, suggesting that this type of correlation analysis might be effective when the samples analyzed were grown under various environmental factors.

\subsection{Effect on PEPCase Activity under Different Nitrogen and Light Conditions}

The nitrogen application would also induce higher photosynthetic activity, and it could enhance the supply of carbon matter into seeds. Therefore, there is a possibility that the enhancement of carbon transport into seeds induces higher seed PEPCase activity. To test this possibility, we examined the effect of the nitrogen supply under normal sunlight and shaded (50\% light) conditions. As shown in Figure 4, between the normal sunlight and shaded conditions, we observed no clear effect on PEPCase activity (no significant difference). In the shaded condition, the enzyme activity of the High-N-S plot was approx. 0.3-fold higher than that of the Low-N-S plot, although the difference was not significant $(\mathrm{P}=0.101$ by t-test). These results imply that the nitrogen supply in the grain-filling stages has a greater effect on the PEPCase activity in developing seeds than the supply of sunlight.

\section{Discussion}

In the present study, we tested the relationship between the PEPCase activity and protein content in wheat seeds under the four different growth conditions. The enzyme activity in developing seeds and the protein content in mature seeds appeared to be affected by the nitrogen utilization status. The relationship that we observed between the two factors supports the hypothesis that PEPCase is a key enzyme in the biological mechanism underlying the changes in seed protein content. This field experimental record provides useful information about nutrient control for further analyses. 


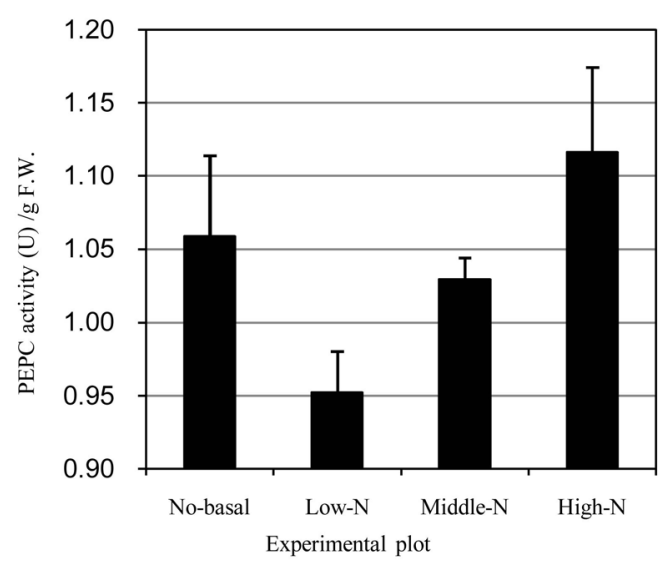

(a)

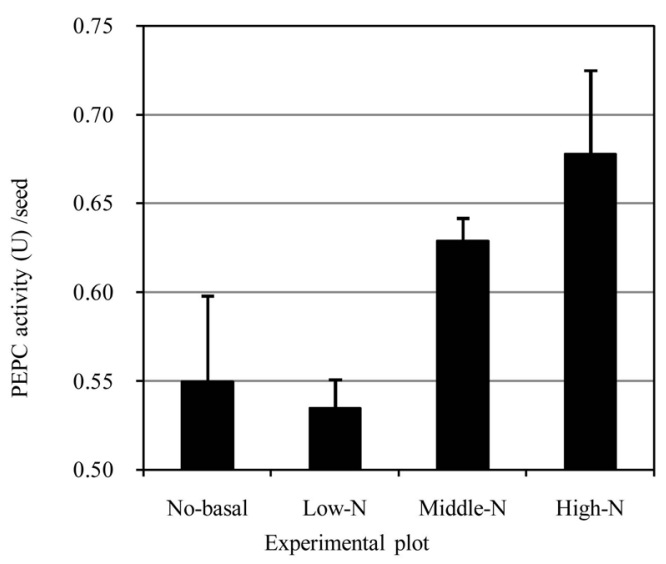

(b)

Figure 1. PEPCase activity in developing wheat seeds. (a) PEPCase activity per fresh weight; (b) PEPCase activity per seed. Error bars: standard deviation.

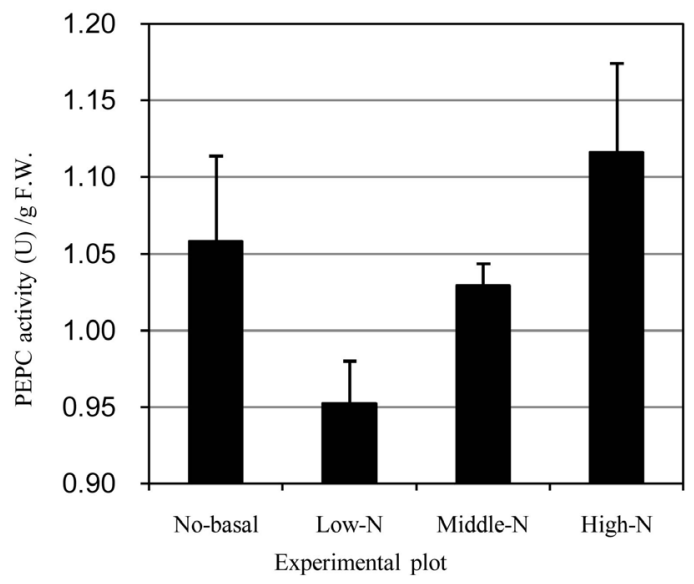

Figure 2. The protein content in mature wheat seeds.

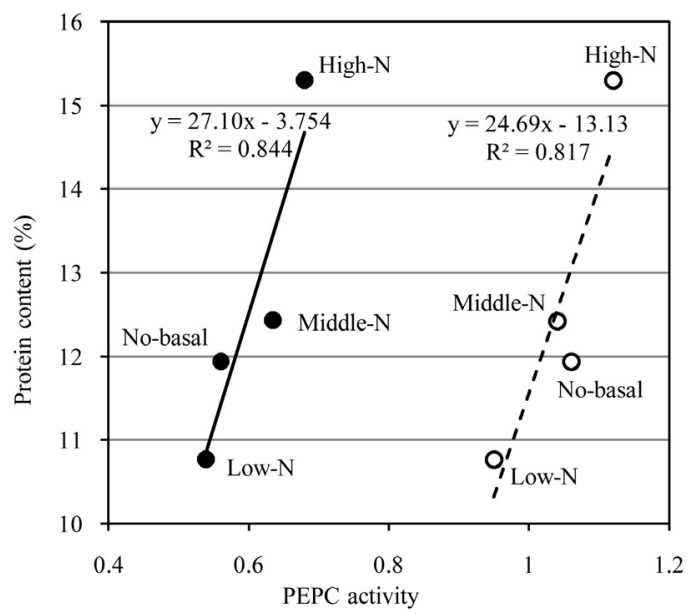

Figure 3. The relationship between the PEPCase activity and protein content. The $\mathrm{x}$-axis represents the PEPCase activity in the developing seeds, and the y-axis represents the protein content in the mature seeds. Open circles: The enzyme activity per fresh weight (g). Closed circles: The enzyme activity per seed. Bold and broken lines represent linearization obtained MS Excel. The corresponding approximate formula and the coefficient of determination are presented near each line. 


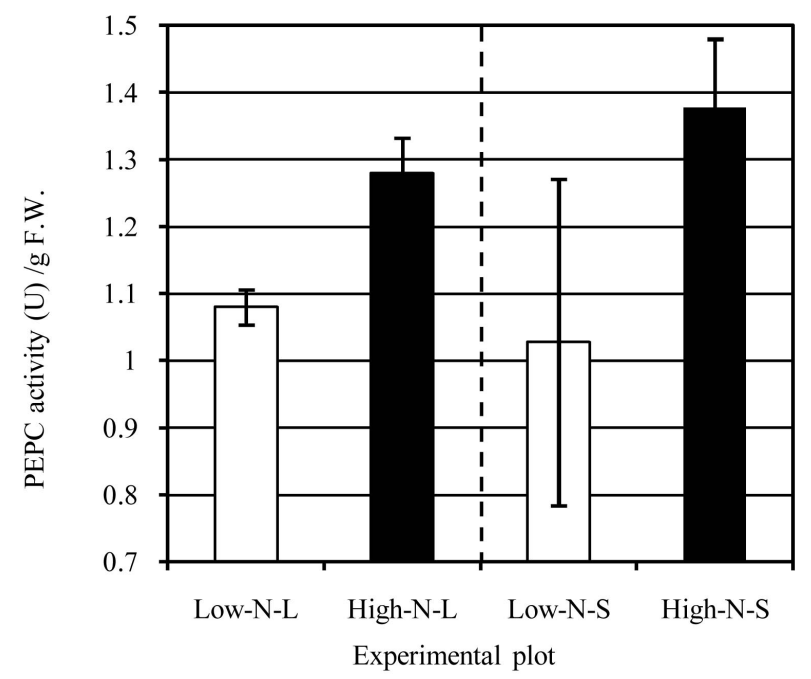

Figure 4. PEPCase activity in developing wheat seeds under hydroponics. Error bars: standard deviation.

The application levels of nitrogen in the fields were $0.88 \mathrm{~g}$ and $2.65 \mathrm{~g}$ of nitrogen per $\mathrm{m}^{2}$ in the Middle- $\mathrm{N}$ and High-N plots, respectively. These levels were quite lower than the level that is commonly used to increase the wheat protein content in Japan, $4 \mathrm{~g}$ of nitrogen per $\mathrm{m}^{2}$. Nevertheless, the effect of the nitrogen fertilization on the PEPCase activity and protein content was evident. This result indicates that the PEPCase activity in developing wheat seeds was expressed under strict regulation related to seed protein accumulation. On the other hand, our hydroponic culture experiment revealed a clearer effect of the high nitrogen treatment on PEPCase activity, indicating that the application of a higher level of nitrogen in our field experiment would have resulted in a more distinct relationship between the PEPCase activity and the seed protein content.

Considering the metabolic function of PEPCase, this enzyme might be activated by the carbon supply. The nitrogen application would increases the photosynthetic activity in leaves, and this would achieve translocation from source organs to seeds. If the carbon supply affects PEPCase, a lower amount of sunlight could have a negative effect on the enzyme activity. However, the effect of shade on PEPCase in the hydroponic culture was unclear in this study. It is difficult to conclude that PEPCase in developing wheat seeds was unaffected by the light supply, because we conducted this experiment under only one condition (light cut by 50\%). Further studies should be carried out to address this issue.

In the past decade, it has been emphasized the relationship between PEPCase and nitrogen accumulation in plant seeds. The overexpression of Corynebacterium PEPCase altered the seed metabolism and increased the protein content of narbon bean [13]. A PEPCase isogene in rice, Osppc1, was highly expressed at 8 to 14 days after flowering, a time at which nitrogen accumulation in seeds was active [12]. In addition, Osppc1 was co-expressed with aspartate aminotransferase and alanine transaminase [12]. These studies indicate two potential functions of PEPCase in developing seeds: one is that the enzyme is one of the factors that determine the ability of importing nitrogen into seeds, and the other is that the enzyme complements organic acids to utilize imported nitrogen compounds for biosynthesis of storage proteins.

The genetic variance of PEPCase activity and protein content provides further support for involvement of PEPCase in nitrogen metabolism in developing seeds. The variety Norin 61 has a genetic trait in which both the PEPCase activity and seed protein content respond to the nitrogen supply. The role of PEPCase may be further clarified by comparing this wheat variety to others which show a lesser response to the nitrogen supply, such as Fukusayaka [19]. Alternatively, a comparison to a variety that shows a higher seed protein content may reveal the contribution of PEPCase to protein accumulation in seeds.

\section{Conclusion}

PEPCase activity in developing wheat seeds seems to be induced by nitrogen application at a flowering stage. The underlying mechanism may be the activation of the biosynthesis of seed storage protein. The results of the 
present study will contribute to further analyses of PEPCase in wheat seeds toward the goal of the effective production of wheat grains.

\section{Acknowledgements}

This work was supported by the Tojuro Iijima Foundation for Food Science and Technology.

\section{References}

[1] Shewry, P.R. and Halford, N.G. (2002) Cereal Seed Storage Proteins: Structures, Properties and Role in Grain Utilization. Journal of Experimental Botany, 53, 947-958. http://dx.doi.org/10.1093/jexbot/53.370.947

[2] Ribeiro, M., Nunes-Miranda, J.D., Branlard, G., Carrillo, J.M., Rodriguez-Quijano, M. and Igrejas, G. (2013) One Hundred Years of Grain Omics: Identifying the Glutens That Feed the World. Journal of Proteome Research, 12, 47024716. http://dx.doi.org/10.1021/pr400663t

[3] Peña, R.J. (2002) Wheat for Bread and Other Foods. In: Curtis, B.C., Rajaram, S. and Macpherson, H.G., Eds., Bread Wheat-Improvement and Production, FAO Plant Production and Protection Series, Rome, 30.

[4] Shewry, P.R. (2009) Wheat. Journal of Experimental Botany, 60, 1537-1553. http://dx.doi.org/10.1093/jxb/erp058

[5] Zörb, C., Steinfurth, D., Seling, S., Langenkämper, G., Koehler, P., Wieser, H., Lindhauer, M.G. and Mühling, K.H. (2009) Quantitative Protein Composition and Baking Quality of Winter Wheat as Affected by Late Sulfur Fertilization. Journal of Agricultural and Food Chemistry, 57, 3877-3885. http://dx.doi.org/10.1021/jf8038988

[6] Hawkesford, M.J. (2014) Reducing the Reliance on Nitrogen Fertilizer for Wheat Production. Journal of Cereal Science, 59, 276-283. http://dx.doi.org/10.1016/j.jcs.2013.12.001

[7] Sylvester-Bradley, R. and Kindred, D.R. (2009) Analysing Nitrogen Responses of Cereals to Prioritize Routes to the Improvement of Nitrogen Use Efficiency. Journal of Experimental Botany, 60, 1939-1951. http://dx.doi.org/10.1093/jxb/erp116

[8] Wan, Y., Gritsch, C.S., Hawkesford, M.J. and Shewry, P.R. (2014) Effects of Nitrogen Nutrition on the Synthesis and Deposition of the $\omega$-Gliadins of Wheat. Annals of Botany, 113, 607-615. http://dx.doi.org/10.1093/aob/mct291

[9] O’Leary, B., Park, J. and Plaxton, W.C. (2011) The Remarkable Diversity of Plant PEPC (Phosphoenolpyruvate Carboxylase): Recent Insights into the Physiological Functions and Post-Translational Controls of Non-Photosynthetic PEPCs. Biochemical Journal, 436, 15-34. http://dx.doi.org/10.1042/BJ20110078

[10] Sugimoto, T., Tanaka, K., Monma, M., Kawamura, Y. and Saio, K. (1989) Phosphoenolpyruvate Carboxylase Level in Soybean Seed Highly Correlates to Its Contents of Protein and Lipid. Agricultural and Biological Chemistry, 53, 885887. http://dx.doi.org/10.1271/bbb1961.53.885

[11] Sugimoto, T., Sueyoshi, K. and Oji, Y. (1997) Increase of PEPC Activity in Developing Rice Seeds with Nitrogen Application at Flowering Stage. In: Ando, T., Fujita, K., Mae, T., Matsumoto, H., Mori, S. and Sekiya, J., Eds., Plant Nutrition for Sustainable Food Production and Environment-Proceedings of the 13th International Plant Nutrition Colloquium, Tokyo, 13-19 September 1997, Springer, Netherlands, 811-812.

[12] Yamamoto, N., Kubota, T., Masumura, T., Shiraishi, N., Tanaka, K., Sugimoto, T. and Oji, Y. (2014) Molecular Cloning, Gene Expression and Functional Expression of a Phosphoenolpyruvate Carboxylase Osppc1 in Developing Rice Seeds: Implication of Involvement in Nitrogen Accumulation. Seed Science Research, 24, 23-36. http://dx.doi.org/10.1017/S0960258513000354

[13] Radchuk, R., Radchuk, V., Götz, K.P., Weichert, H., Richter, A., Emery, R.J., Weschke, W. and Weber, H. (2007) Ectopic Expression of Phosphoenolpyruvate Carboxylase in Vicia narbonensis Seeds: Effects of Improved Nutrient Status on Seed Maturation and Transcriptional Regulatory Networks. The Plant Journal, 51, 819-839. http://dx.doi.org/10.1111/j.1365-313X.2007.03196.x

[14] Araus, J.L., Bort, J., Brown, R.H., Bassett, C.L. and Cortadellas, N. (1993) Immunocytochemical Localization of Phosphoenolpyruvate Carboxylase and Photosynthetic Gas-Exchange Characteristics in Ears of Triticum durum Desf. Planta, 191, 507-514. http://dx.doi.org/10.1007/BF00195752

[15] González, M.C., Osuna, L., Echevarría, C., Vidal, J. and Cejudo, F.J. (1998) Expression and Localization of Phosphoenolpyruvate Carboxylase in Developing and Germinating Wheat Grains. Plant Physiology, 116, 1249-1258. http://dx.doi.org/10.1104/pp.116.4.1249

[16] Hoagland, D.R. and Arnon, D.I. (1950) The Water-Culture Method for Growing Plants without Soil. California Experiment Station Circular No. 347. The College of Agriculture, University of California, Berkeley.

[17] Kjeldahl, J.G.C.T. (1883) Neue methode zur bestimmung des stickstoffs in organischen körpern. Fresenius’ Journal of Analytical Chemistry, 22, 366-382. http://dx.doi.org/10.1007/BF01338151 
[18] Echevarria, C., Pacquit, V., Bakrim, N., Osuna, L., Delgado, B., Arrio-Dupont, M. and Vidal, J. (1994) The Effect of $\mathrm{pH}$ on the Covalent and Metabolic Control of C4 Phosphoenolpyruvate Carboxylase from Sorghum Leaf. Archives of Biochemistry and Biophysics, 315, 425-430. http://dx.doi.org/10.1006/abbi.1994.1520

[19] Ishikawa, N., Nagamine, T., Yanaka, M., Takayama, T., Taya, S., Kai, Y., Tanio, M., Sato, J., Murakami, Y. and Sumida, T. (2005) Bulletin of NARO Western Region. Agricultural Research Center, 4, 25-37. 
Scientific Research Publishing (SCIRP) is one of the largest Open Access journal publishers. It is currently publishing more than 200 open access, online, peer-reviewed journals covering a wide range of academic disciplines. SCIRP serves the worldwide academic communities and contributes to the progress and application of science with its publication.

Other selected journals from SCIRP are listed as below. Submit your manuscript to us via either submit@scirp.org or Online Submission Portal.
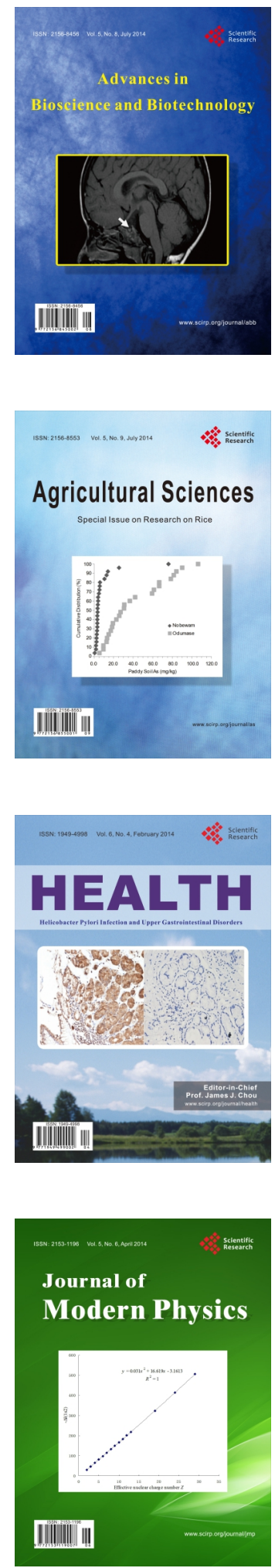
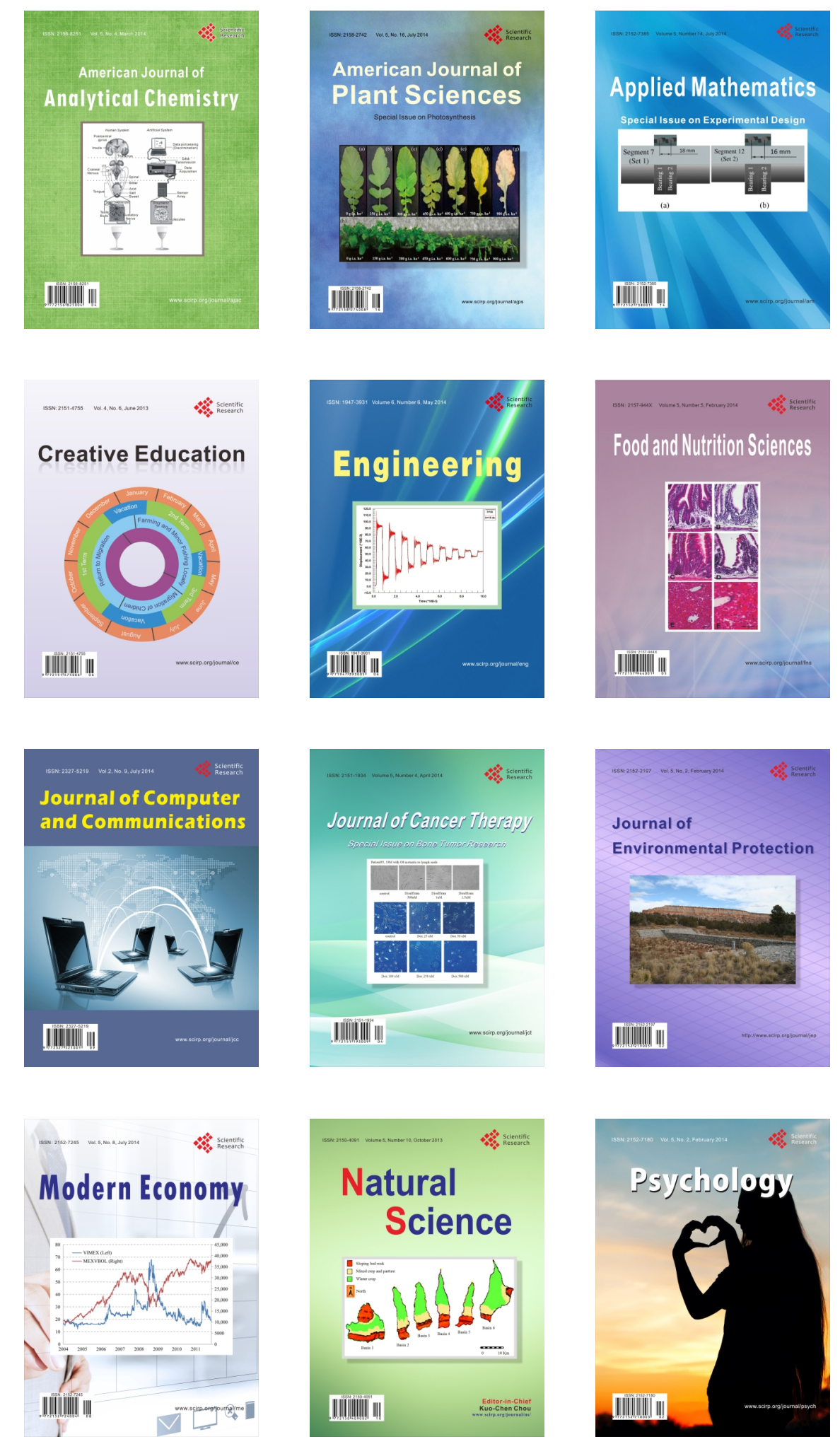